\title{
Spatio-Temporal Analysis of Landuse/Landcover Change of District Pishin Using Satellite Imagery and GIS
}

\author{
Sanaullah Khan*, Said Qasim, Romana Ambreen, Zia-Ul-Haq Syed \\ Department of Geography, University of Balochistan, Quetta, Pakistan \\ Email: sana.geo1@gmail.com
}

Received 28 April 2016; accepted 6 June 2016; published 9 June 2016

Copyright $@ 2016$ by authors and Scientific Research Publishing Inc.

This work is licensed under the Creative Commons Attribution International License (CC BY). http://creativecommons.org/licenses/by/4.0/

(c) (i) Open Access

\begin{abstract}
Detecting change on the face of the globe using GIS (Geographic Information System) aided by remotely sensed imagery is now becoming an indispensable tool in managing the resources of our planet. The present study with the help of GIS and remote sensing (RS) is also a similar attempt in recording and quantifying change in land use and land cover in district Pishin both in spatial and temporal extents. Satellite imagery was acquired from the USGS official website from three LANDSAT satellites. Theses satellites are LANDSAT 5, LANDSAT7 and LANDSAT 8. The data were acquired for the years 1992, 2003 and 2013. Satellite imagery was processed in ArcMap 10.1 and maximum likelihood supervised image classification was applied in reaching the goal of detecting change. The result of the analysis revealed that built-up area was increased by $5.84 \%$; vegetation was increased by $3.89 \%$; water bodies were increased by $0.05 \%$ and bare surfaces were decreased by $9.78 \%$. The decrease in the barren surfaces was attributed to the increase in vegetation and built-up area which replaced the barren land in the study area. This paper also shows the significance and potential of digital change detection methods in managing the resources of our environment and keeping an eye on the land use and land cover of our Earth.
\end{abstract}

\section{Keywords}

Spatial-Temporal, Land-Cover Change, District Pishin, GIS, Satellite Imagery

\section{Introduction}

Scientific studies have shown that there are only few places left on the face of the earth which are still in their

"Corresponding author.

How to cite this paper: Khan, S., Qasim, S., Ambreen, R. and Syed, Z.-U.-H. (2016) Spatio-Temporal Analysis of Landuse/Landcover Change of District Pishin Using Satellite Imagery and GIS. Journal of Geographic Information System, 8, 361-368. http://dx.doi.org/10.4236/igis.2016.83031 
natural state, and are not altered due to human involvement and activities. Anthropogenic activities along with some natural process have greatly altered the natural state of the face of earth. Land use/land cover (LULC) pattern of an area is almost entirely defined by human and natural activities [1]. Therefore, LULC change detection studies have become extremely important for monitoring our environment and using the resources of the mother Earth in a judicious way [2]. Observing Earth from space using satellite imagery is playing decisive role in monitoring and keeping an eye on human influence on Earth's environment and resources available for our utilization [3]. Detecting change digitally helps in determining the changes that have occurred in land use and land cover with the help of geo-referenced multi-dimensional remotely sensed data [4]. Satellite imagery with various spatial, temporal, spectral and radiometric resolutions is used for the purpose of change detection both in spatial and temporal extents in the study area. These images with various data specifications can be acquired in numerous formats from various data providing web sources for free or by paying to the data providers [5]. It should be kept in mind that the data that are available for free are mostly in less spatial resolutions but can effectively be used in land use change detection. For any kind of digital change detection, it is necessary to classify the imagery that is pre-processed and enhanced if necessary [6]. The imagery that is acquired can be processed in various GIS software packages using various methods such as supervised and unsupervised classification after its Geo-registration and enhancements [7]. The digital process of Maximum Likelihood as a common method is mostly used for detecting change in variety of geographical setups [8]. Supervised classification is still one of the most widely used supervised classification methods [9]. This process is also considered trustworthy and accurate [10]. GIS as tool was used in detecting land use change in the study area in its spatial and temporal arenas. To accomplish this, a very sophisticated GIS software package called ArcMap 10.1 was used for handling satellite imagery. In addition to the satellite data from different LANDSAT sensors, topographic sheets were also used in reaching the goal of digital change detection in the study area.

The availability of imagery of the desire dates is one of the limitations of the study along with the availability of very high resolution satellite images. The research is carried out on a topic that is of great importance in keeping an eye on resources of the Earth using the GIS and remote sensing.

\section{Methodology}

\subsection{Study Area}

District Pishin is situated in North West of Balochistan province of Pakistan (Figure 1), and is geographically gifted with lofty mountains and intermountain plateau, with scattered plain areas in form of piedmont plains. The absolute location of District Pishin is $30^{\circ} 04^{\prime}$ to $31^{\circ} 17^{\prime}$ North and $66^{\circ} 13^{\prime}$ to $67^{\circ} 50^{\prime}$ East [11]. The total area of district Pishin is $5296 \mathrm{sq} \mathrm{km}$. Pishin district has a climate with mild summers and very cold winters.

Eleven inches of precipitation per annum depicts the dry and semiarid climate of the province. The Geographical location of the district is on the margin of the prominent weather systems of the subcontinent that are the summer and winter Monsoon.

\subsection{Data Sources and Acquisition}

For the purpose of land use and land cover change detection data from different LANDSAT sensors was used. The data in from of satellite imagery was acquired from the USGS official website from three LANDSAT satellites. The first one is LANDSAT 5 carrying TM (Thematic Mapper) senor. Imagery for the year 1992 was downloaded from this sensor. The second one is LANDSAT7 carrying the ETM+ (Enhanced Thematic Mapper) sensor. Imagery for the year 2003 was downloaded from this sensor, and the third one is LANDSAT 8 carrying OLI (Operational Land Imager) sensor. Imagery for the year 2013 was downloaded from this sensor. The data that was acquired from these sensors was of a fairly larger temporal extent of around 21 years (1992-2013) and also was of considerable spectral resolution. Topographic sheets were acquired from survey of Pakistan and were used in the process of class making and change detection.

\subsection{Data Analysis}

Image classification is a joint human and computer attempt to identify land use/land cover classes present in the imagery by using the spectral information that is stores in the imagery in form of digital number values. To find out the land use and land cover change, the satellite imagery was classified in ArcMap 10.1. For this study the 


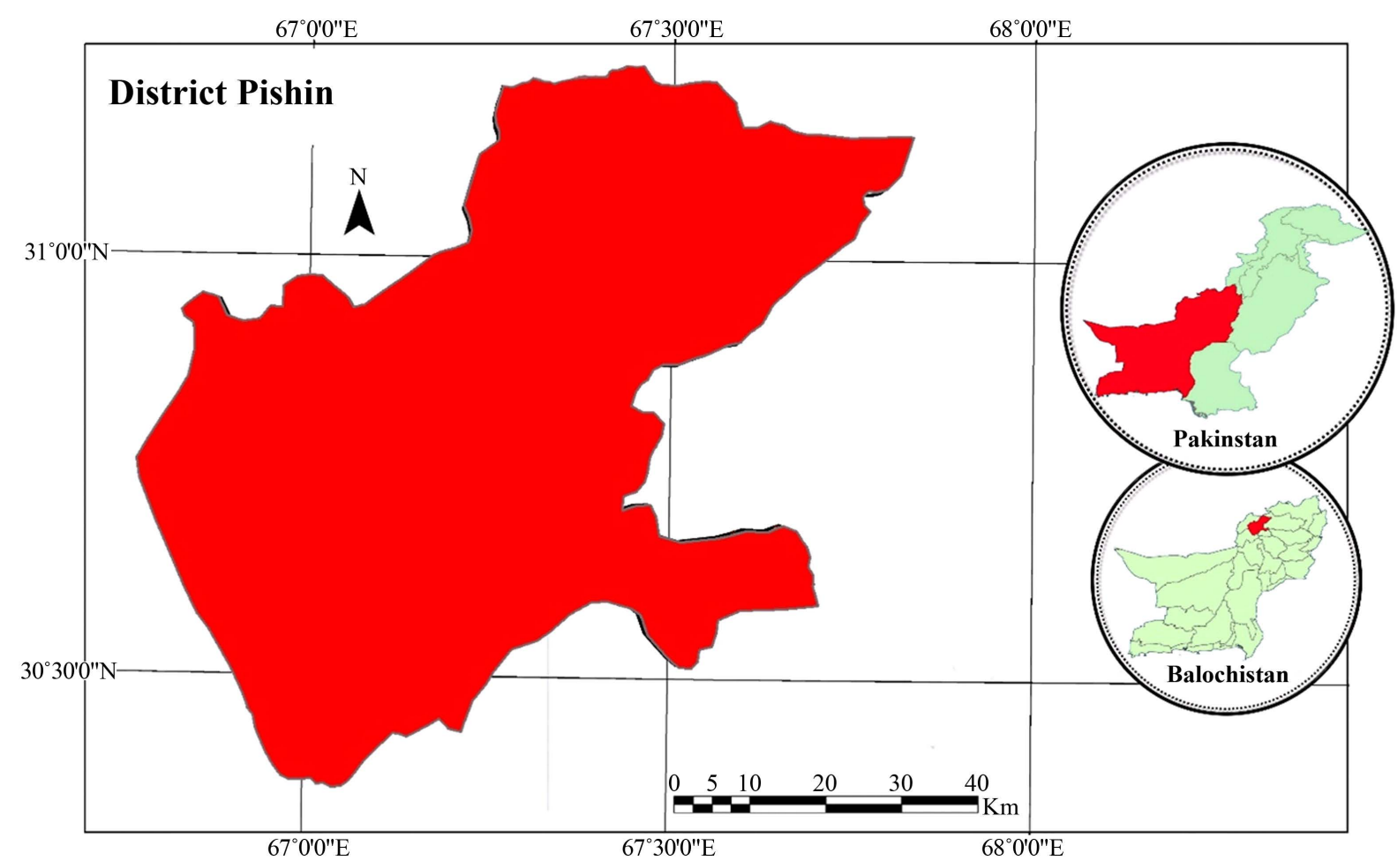

Figure 1. Location map of district Pishin.

process of supervised classification was performed using the maximum likelihood supervised classification script. During this process of supervised classification training samples were selected with great care, and each LULC class was identified with the help of pan-sharpened imagery and topographic maps. It is pertinent to mention that the personal observation and knowledge of the study area also helped in the classification process. Post classification accuracy assessment was performed using the error matrix method. The accuracy assessment confirmed the accuracy of the classification process. Four land use and land cover classes were identified for the detection of change in the study area. The details of these classes are given in Table 1.

\section{Results and Discussions}

All the three images that were processed and classified were used to reach the goal of LULC change detection. As mentioned earlier that all the three images of the year 1992, 2003 and 2013 were classified using the maximum likelihood supervised classification. The results of the classification are discussed below in detail.

\section{Results of 1992 Classified Image}

According to the results of the classified image (Figure 2) the bare surfaces dominates the total area and covers $88.03 \%$ which is followed by built-up area which covers $6.56 \%$. The water bodies cover the least of land area and covers only $0.13 \%$ of the total area. Accuracy assessment was also performed for the classified image. The results of the image indicate that user's accuracy for all the classes is very good except water which is about $84 \%$. This can be attributed to the same spectral responses of some water pixels as that of some darkish rocks in the class bare surfaces. The overall accuracy of classification is also very good, which is around $89 \%$.

\section{Results of 2003 Classified Image}

According to the results of the classification (Figure 3) water bodies covers the least part of the total area which is $0.14 \%$ or 1836.54 acres. Barren land covers a major chunk of the total area which is $81.62 \%$ or $1,068,335.01$ acres. The vegetation covers $7.69 \%$ or $100,669.02$ acres. The buildup area covers about $137,834.54$ acres or $10.53 \%$ of the total area. The resultant map of the image of the year 2003 that was classified for the purpose of land use and land cover change detection can be seen in Figure 3. Accuracy assessment of the 2003 image clearly indicates that the bare surfaces were most accurately classified. This can be attributed to the reason that a large portion of the study area comprises this land cover type. The leas accurately class is again 


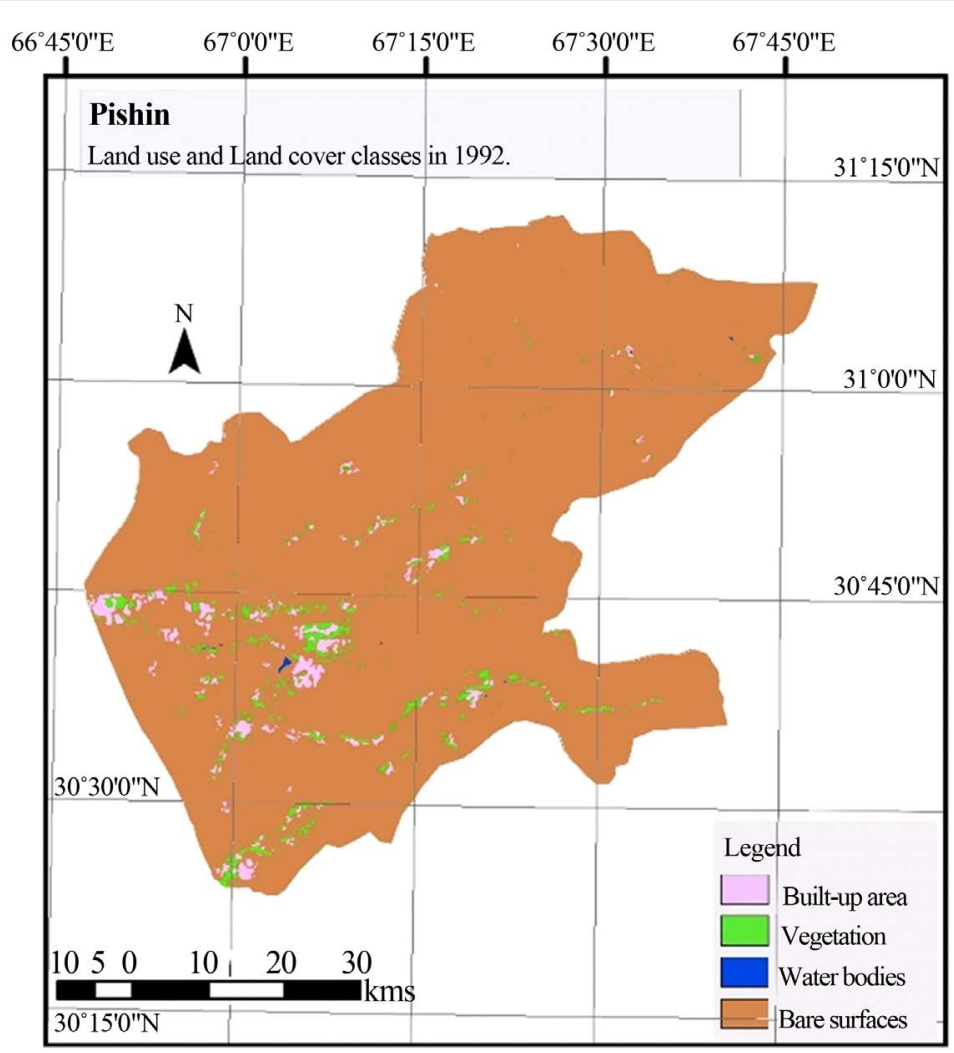

Figure 2. Land use and land cover classification for the year 1992.

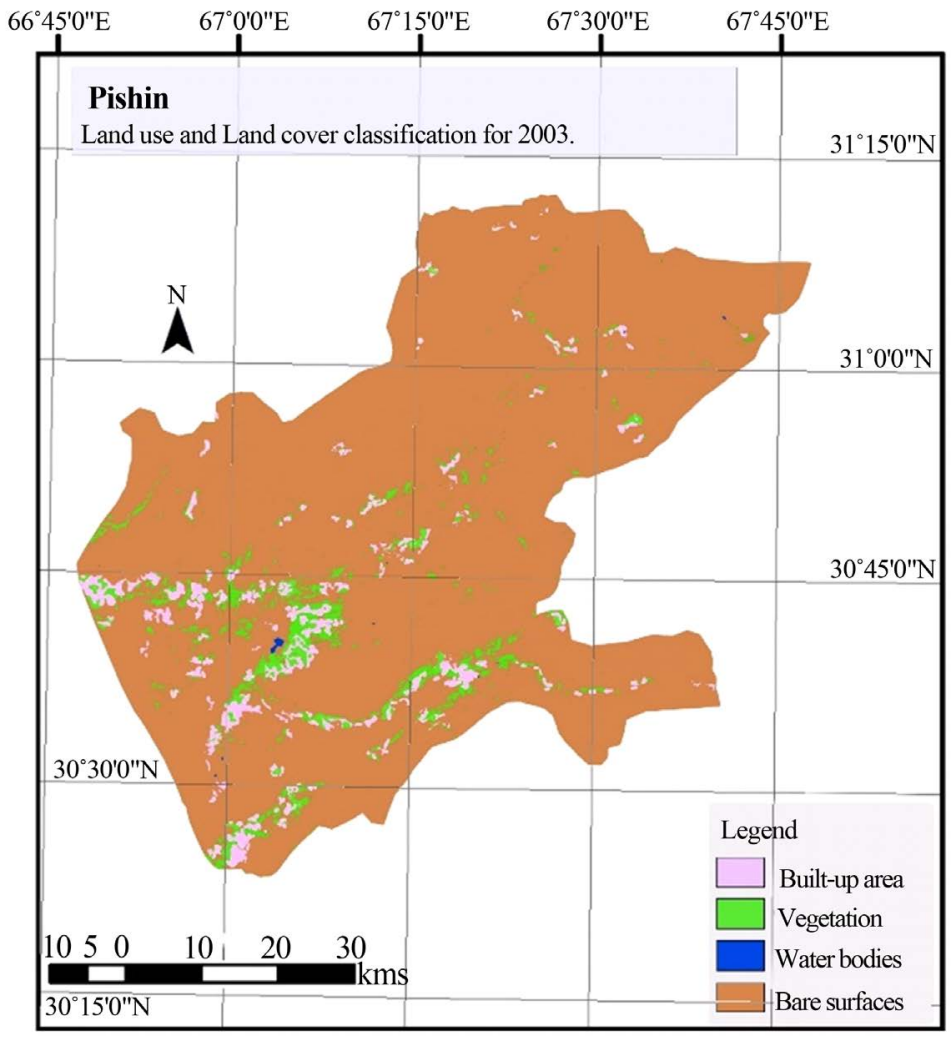

Figure 3. Land use and land cover classification for the year 2003. 
Table 1. Showing land use land cover classes.

\begin{tabular}{ccc}
\hline & Class & Description \\
\hline 1 & Bare surfaces & Areas with no vegetation cover, soil, stony areas, uncultivated agricultural lands. \\
2 & Vegetation & All kind of green plants, trees, grass. \\
3 & Water bodies & Dam, river, lake. \\
4 & Built-up area & Settlements like Town, city and village etc. \\
\hline
\end{tabular}

water which is $86 \%$ this can be attributed to the reason that some pixels in the image that were covering the mountainous portion of study area were having same spectral characteristics as that of water.

\section{Results of 2013 Image Classification}

The results of the classification (Figure 4) shows that barren land still occupies a major chunk of the total area which is $78.25 \%$ or $1,024,043.97$ acres followed by built-up area which covers $12.40 \%$ or $162,303.31$ acres. The vegetation covers $9.17 \%$ or $120,016.27$ acres. Water bodies covers only $0.18 \%$ or 2311.57 acres. Accuracy assessment of the classification depicted that most accurately classified class is bare surfaces which constitutes the major portion of the study area.

This means that about $94 \%$ of the bare surfaces were classified accurately. The least accurately classified class again is water which is $84 \%$ correctly classified. The overall accuracy of the classification is $89 \%$.

\subsection{Land Use and Land Cover Change}

After this detail analysis using satellite imagery that was covering a relatively long temporal span of around 21 it is found that bare surfaces were covering a major chunk of land area which was $88.03 \%$ of the total area of the study area in 1992 this was reduces to $81.63 \%$ in the year 2003 and was further reduced to $78.25 \%$ in the year 2013. Thus an overall $9 \%$ decrease in bare surfaces was recorded during the study period. Built-up area was recorded as $6.57 \%$ of the total area in 1992 which was increased to $10.53 \%$ in the year 2003, and this figure was increased to $12.40 \%$ in the year 2013 . Thus an overall increase of $5.84 \%$ was recorded in this particular land use class. Vegetation was about $5.28 \%$ of the total area in the year 1992 which was increased to $7.69 \%$ in the year 2003 and to $9.17 \%$ in the year 2013. Thus an overall increase of $3.89 \%$ was recorded during the study period. Water bodies was covering $0.13 \%$ in the year 1992 which slightly increased in the year 2003 to $0.14 \%$, the water bodies was further increased to about $0.18 \%$ of the total area in the year 2013 . Thus an overall increase of $0.05 \%$ was recorded during the study period. The detail of the year wise increase or decrease in land use and land cover classification and percent of change is given in Table 2.

\subsection{Findings and Recommendations}

\subsubsection{Findings}

Despite many factors such as availability of imagery for specific time of the year and the availability of recent and updated topographic maps, that created hurdles in finding change in the study area. The present study proved very effective in fulfilling the objectives that were set for the study. The study rendered following findings:

1) The area that is covered by vegetation is gradually increasing. This can be attributed to the increase in number of tube wells and provision of electricity to most part of the study area. As a result of this increase, a number of tube well people is now able to irrigate their fields at interval require for normal growth and production.

2) It was noted that the increase in vegetation is almost entirely restricted to plain southern, south eastern and south western parts of the district. This is because of the availability of cultivatable land in those parts of the study area.

3) It was noted that built-up area increased the most in terms of its proportion to total area. This can be attributed to the increase in agricultural products which in turn increase economic activities and ultimately human settlements and population in the study area.

4) The bare surfaces in the study area are decreasing. This is because the area that was once occupied by the bare surfaces in now covered by vegetation and human settlements. 


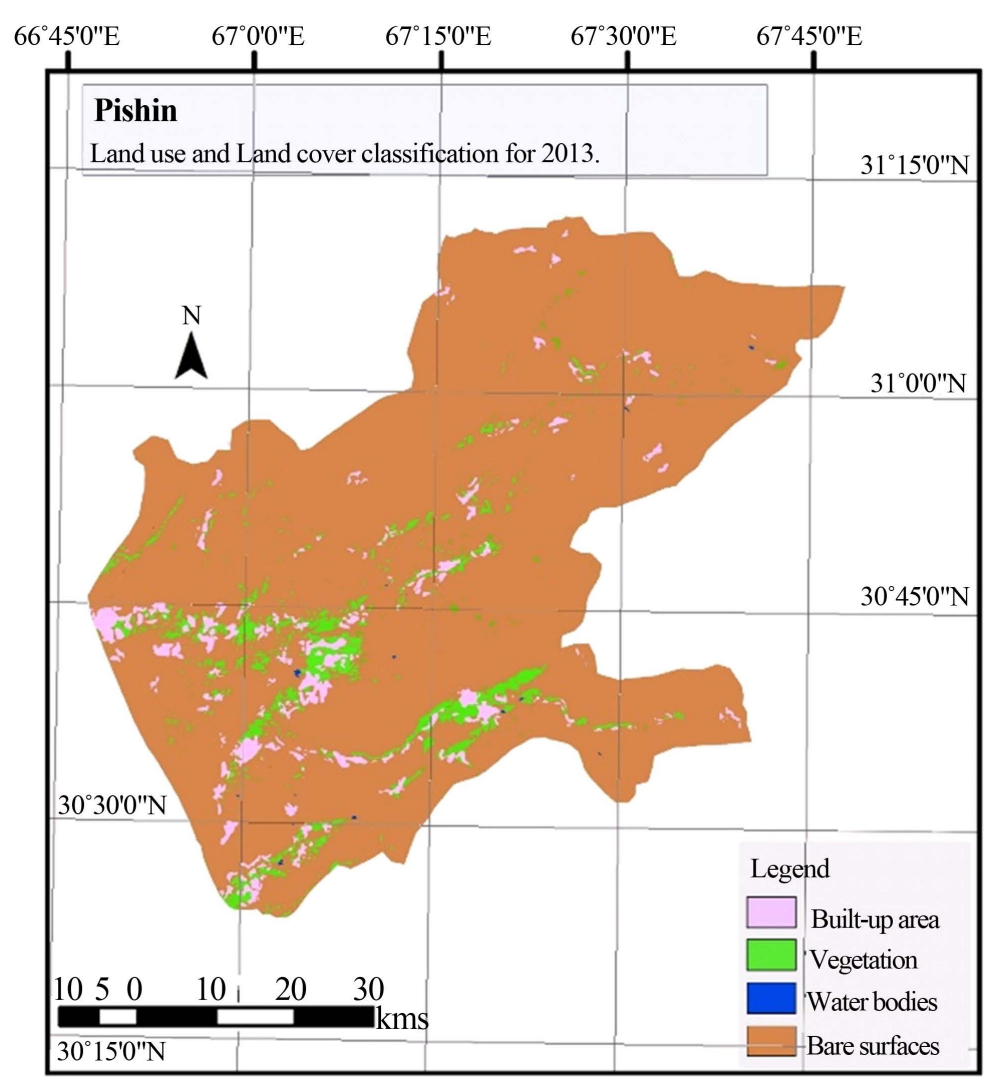

Figure 4. Land use and land cover classification for the year 2013.

Table 2. Year wise area covered by each class and percent of change.

\begin{tabular}{|c|c|c|c|c|c|c|c|}
\hline \multirow{2}{*}{$\begin{array}{l}\text { Land use/Land cover } \\
\text { class }\end{array}$} & \multicolumn{2}{|c|}{1992} & \multicolumn{2}{|c|}{2003} & \multicolumn{2}{|c|}{2013} & \multirow{2}{*}{ Change (\%) } \\
\hline & Hectares & $(\%)$ & Hectares & $(\%)$ & Hectares & $(\%)$ & \\
\hline Built-up area & $34,725.51$ & 6.57 & $55,779.66$ & 10.53 & $65,681.82$ & 12.40 & 5.84 \\
\hline Vegetation & $27,985.86$ & 5.28 & $40,739.31$ & 7.69 & $48,568.86$ & 9.17 & 3.89 \\
\hline Water bodies & 668.88 & 0.13 & 743.22 & 0.14 & 935.46 & 0.18 & 0.05 \\
\hline Bare surfaces & $466,221.78$ & 88.03 & $432,339.84$ & 81.63 & $414,415.89$ & 78.25 & -9.78 \\
\hline
\end{tabular}

5) Water bodies in the study area have increased with very slow speed, and have increased only $0.05 \%$ in around 21 years. This is because the area is experiencing dry spells in the recent times.

6) The area covered by barren surfaces is mostly decreased in the plain southern, south eastern and south western parts of the district.

7) The little increase in the water bodies is due to the construction of small dams on seasonal streams that runs through the study area.

8) The buildup area increased in most parts of the district, especially in the plain southern, south eastern and south western parts of the district.

9) The Lake Kushdil khan in central southern part of the study area is the still the largest water body, but the area covered by it has shrunken over the time.

10) On the basis of current finding it can be predicted that the barren land will continue to shrink and will be replaced by the buildup area and vegetation.

\subsubsection{Recommendations}

The present study is in fact the first attempt in detecting change with the help of GIS and RS in the study area, 
and was carried out with the aid of the freely available satellite imagery. The present study advocates that the use of multi-spectral and multi-temporal imagery can prove very useful for this kind of study. Detecting change using other methods especially using the conventional method often don't works or renders inaccurate results. The study proved that maximum likelihood supervised classification is one of the most suited classification process used for this kind of study. There are many potential possibilities which should be taken in consideration for any future such study. Following recommendations are made in this regard:

1) The present study was carried out with the aid of medium resolution freely available imagery. The imagery was having medium spectral and spatial resolutions. As a results of this the chances of misclassification increases. Therefore commercially available satellite imagery with very high spatial and spectral resolution can be used for much accurate results.

2) Differential GPS can be used for the collection of the reference data for accuracy assessment. Reference points collected with the aid of the differential GPS can render more accurate results while assessing the post classification accuracy.

3) New and updated topographic maps can be used, which will certainly help in the process of classification and class identification.

4) Colored aerial photographs can certainly help in the process of classification and class identification. Such photographs should be used if available.

5) Other methods of classification can used in reaching the goal of land use and land cover change detection.

\section{Conclusion}

Land use and land cover change detection with the help of satellite imagery is important for monitoring environmental changes [12]. The present study that was conducted for the detection of change in land use and land cover in district Pishin with the help of multi-temporal and multi-spectral imagery provided by the United States Geological Survey website from LANDSAT series of the satellites strongly advocates that satellite imagery can effectively be used in detecting change in spatial and temporal extents in almost every part of the globe. Study of such kind if carried without taking the help of GIS and Remote Sensing otherwise would have been impossible if we were to find change that covers such vast temporal and spatial extents. This study reveals that Built-up area was increased by $5.84 \%$; , vegetation was increased by $3.89 \%$; water bodies were increased by $0.05 \%$ and bare surfaces were decreased by $9.78 \%$. The decrease in the barren surfaces was attributed to the increase in vegetation and built-up area which replaced the barren land in the study area. Thus on the basis of the results rendered by this study, it reveals that GIS and RS are currently one of the most effective tools in detection and quantifying change in land use and land cover of particular area.

\section{Acknowledgements}

I am grateful to my supervisor whose indefatigable efforts and fruitful suggestions have made me able to get this work done.

\section{References}

[1] Shoshany, M., Kutiel, P. and Lavee, H. (1996). Monitoring Temporal Vegetation Cover Changes in Mediterranean and Arid Ecosystems Using a Remote Sensing Technique: Case Study of the Judean Mountain and the Judean Desert. Journal of Arid Environments, 33, 9-21. http://dx.doi.org/10.1006/jare.1996.0042

[2] Liu, J. and Deng, X. (2010) Progress of the Research Methodologies on the Temporal and Spatial Process of LUCC. Chinese Science Bulletin, 55, 1354-1362. http://dx.doi.org/10.1007/s11434-009-0733-y

[3] Rogan, J. and Chen, D. (2004) Remote Sensing Technology for Mapping and Monitoring Land-Cover and Land-Use Change. Progress in Planning, 61, 301-325. http://dx.doi.org/10.1016/S0305-9006(03)00066-7

[4] Coppin, P., Jonckheere, I., Nackaerts, K., Muys, B. and Lambin, E. (2004) Review Article Digital Change Detection Methods in Ecosystem Monitoring: A Review. International Journal of Remote Sensing, 25, 1565-1596. http://dx.doi.org/10.1080/0143116031000101675

[5] Reis, S. (2008) Analysing Land Use/Land Cover Changes Using Remote Sensing and GIS in Rize, North-East Turkey. Sensors, 8, 6188-6202. http://dx.doi.org/10.3390/s8106188

[6] Gitas, I.Z., Mitri, G.H. and Ventura, G. (2004) Object-Based Image Classification for Burned Area Mapping of Creus Cape, Spain, Using NOAA-AVHRR Imagery. Remote Sensing of Environment, 92, 409-413. 
http://dx.doi.org/10.1016/j.rse.2004.06.006

[7] Macleod, R.D. and Congalton, R.G. (1998) A Quantitative Comparison of Change-Detection Algorithms for Monitoring Eelgrass from Remotely Sensed Data. Photogrammetric Engineering and Remote Sensing, 64, 207-216.

[8] Zhao, Y. (2003) Principles and Methods for Remote Sensing Application and Analysis. Science Press, Beijing, 415416.

[9] Friedl, M.A., McIver, D.K., Hodges, J.C., Zhang, X.Y., Muchoney, D., Strahler, A.H. and Baccini, A. (2002) Global Land Cover Mapping from MODIS: Algorithms and Early Results. Remote Sensing of Environment, 83, 287-302. http://dx.doi.org/10.1016/S0034-4257(02)00078-0

[10] Mengistu, D.A. and Salami, A.T. (2007) Application of Remote Sensing and GIS Inland Use/Land Cover Mapping and Change Detection in a Part of South Western Nigeria. African Journal of Environmental Science and Technology, 1, 99-109.

[11] Tareen, A.K., Sultan, I.N., Parakulsuksatid, P., Shafi, M., Khan, A., Khan, M.W. and Hussain, S. (2014) Detection of Heavy Metals ( $\mathrm{Pb}, \mathrm{Sb}, \mathrm{Al}, \mathrm{As})$ through Atomic Absorption Spectroscopy from Drinking Water of District Pishin, Balochistan, Pakistan. International Journal of Current Microbiology and Applied Sciences, 3, 293-306.

[12] Landis, J.R. and Koch, G.G. (1977) The Measurement of Observer Agreement for Categorical Data. Biometrics, 33, 159-174. 